This is an electronic reprint of the original article. This reprint may differ from the original in pagination and typographic detail.

Author(s): Nurmi, Jari-Erik

Title: $\quad$ Modeling developmental processes in psychology.

Year: $\quad 2013$

Version:

Please cite the original version:

Nurmi, J.-E. (2013). Modeling developmental processes in psychology.. Perspectives

on Science, 21(2), 181-195. https://doi.org/10.1162/POSC_a_00092

All material supplied via JYX is protected by copyright and other intellectual property rights, and duplication or sale of all or part of any of the repository collections is not permitted, except that material may be duplicated by you for your research use or educational purposes in electronic or print form. You must obtain permission for any other use. Electronic or print copies may not be offered, whether for sale or otherwise to anyone who is not an authorised user. 


\section{Modeling Developmental \\ Processes in Psychology}

Jari-Erik Nurmi

University of Jyväskylä

In the present article I suggest first that modeling in psychology can be described as an interactive process between a phenomenon under study (reality) and different levels of theoretical conceptualizations that vary in respect to how directly they can be related to empirical observations and at what level of generalization they operate. Then, I give three examples of my own work concerning building theories and testing models. Next, I discuss some caveats scientists face when building theories and models on the basis of their observations. Finally, I make a few conclusions on the basis of the article.

\section{Introduction}

In their effort to understand some phenomena, mechanisms, or relations between them, scientists observe reality and construct theories and models to explain their observations. The process is interactive: On the one hand, observations lead to formulating certain models and theories. On the other hand, models and theories direct scholars' observations, because they include conceptualizations of reality and also ideas how the observations should be made. Scientists, in fact, behave just like any human being and most of the animals: all create representations and schemata concerning their living environments which then later on help them to behave in adaptive ways (Neisser 1976).

Compared to everyday observations that guide constructing representations of the external world, scientists' efforts are more conscious, goaldirected, and governed by many rules concerning what are appropriate ways of theory building. What is particularly typical for science is that there are a number of different criteria for evaluating the validity and reliability of the observations, as well as testing the extent to which theories 


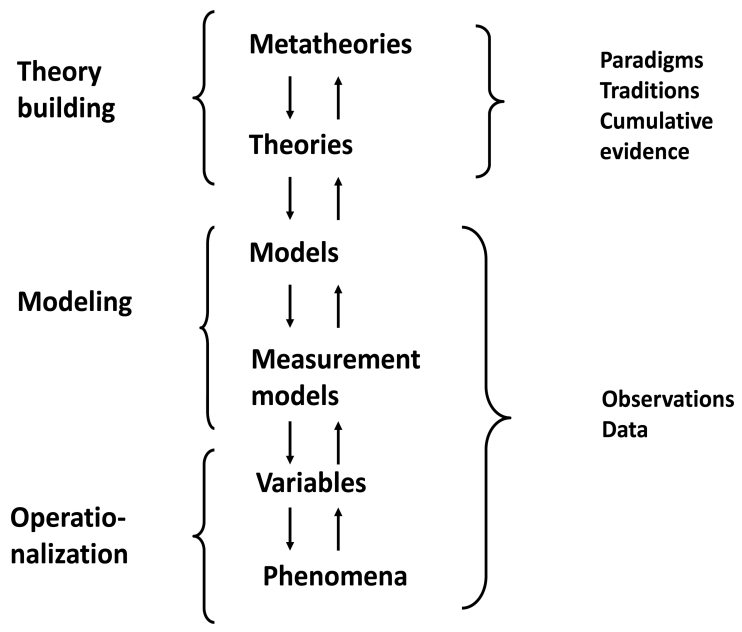

Figure 1. Interaction between different levels of modeling.

and models are in accordance with observations (Nurmi 2012). Different disciplines and even different fields of a particular discipline have somewhat different views of how this process of forming theories and models on the basis of observations should proceed. In the present article I discuss first the ways in which modeling is understood in psychology. Then, I give three examples of my own work concerning building theories and testing models. Next, I discuss some caveats scientists face when building theories and models on the basis of their observations. Finally, I make a few conclusions.

\section{Modeling in Psychology}

Modeling in psychology can be described as an interactive process between a phenomenon under study and different levels of theoretical conceptualizations that vary with respect to how directly they can be related to empirical observations (or data) and at what level of generalization they operate. This interactive process is described in Figure 1 in terms of three levels that each include two sublevels: theory building (meta-theories and theories), modeling (models and measurement models), and operationalization (variables and phenomena; Nurmi 2012). This is somewhat similar approach to that suggested by Suppes (1962) fifty years ago.

First, at the most abstract and general level meta-theories (e.g., theories like learning theory or psychoanalysis) consist of general principles that describe some research field (Figure 1). Although they impact building more specific theories, they are formulated in such general terms that they 
cannot be falsified by individual studies or experiments. The next level, theories (e.g., learned helplessness theory), are more concrete and articulated but, as with meta-theories, they seldom can be falsified on the basis of a single study. One key notion presented in Figure 1 is that different levels of theoretical conceptualizations interact with each other. In the long run, the development of new theories may influence meta-theories by changing the current paradigms in a particular research field. Similarly, theories are often derived from some key principles of meta-theories.

The second level is described as modeling. At this level, there are two sublevels. The first sublevel is models (being derived from theories) which are typically detailed and concrete enough to be tested and falsified on the basis of empirical data. Another sublevel of the modeling is testing measurement models. Theories typically include some key constructs that provide a basis for the construction of measurement models. Testing measurement models includes investigating whether a certain theoretical construct can be measured in reliable and valid ways.

The third part of modeling includes operationalization of the key constructs in terms of variables that provide a basis for creating measurement models for key constructs. Different theories typically have assumptions of what are the appropriate ways to measure the key variables and make sure they reflect the phenomenon under interest in valid ways. Variables are assorted observations of the phenomena under interest.

The interactive nature of modeling is also evidenced in the fact that different levels of modeling are influenced by both reality and scientific practices and traditions in the research field. This, in fact, makes science a dynamic activity. For scholars aiming at understanding reality it is important to understand this dynamic interaction between observations of reality and the role of research traditions in their research activity.

Each level of modeling also serves different functions in science. Metatheories typically provide a tool to understand broader research field. For example, the principles of learning theory have also been used to understand, besides learning, many fields of psychology from child development to the development of psychiatric disorders. Theories are typically employed as a means to direct empirical research and to understand observations found in this research. When theories are not able to fruitfully direct new findings they are abandoned and new theories created. In turn, models are used to test broader theories by using data from concrete studies. Models can be falsified and if many models being derived from a particular theory have been falsified this typically leads to reformulation of a particular theory. They key function of operationalization of variables and testing measurement models is to make sure that the observations are made in valid and reliable fashion (Nurmi 2012). 


\section{Examples of Modeling in Psychology}

Next, I give a few examples of modeling in psychology. The examples include both construction of a theory (example 1), as well as creating a model and testing it with an empirical data (examples 1 and 2).

\section{Example 1: A Theory of Future Orientation}

In the late 1980s, I became interested in how adolescents see their future. At that time future orientation was described by using several dimensions: the content of hopes and goals people had concerning their future (e.g., education, occupation, family, leisure, friends, etc.), how far into the future people's thinking extended (extension), and the kinds of beliefs individuals had concerning their future (e.g., control beliefs, affects; Trommsdorff, Lamm \& Schmidt 1979). The key focus of research at that time was how some individual differences, such as ability to "delay gratification" and impulse control (Mischel and Grusec 1967), impact future orientation. The key assumption was that young people who are unable to delay gratification and control their impulses are in danger of getting problems in their life, such as low education, teenage pregnancy, and poorly paid jobs.

I became gradually dissatisfied with this theory, and for the following reasons: First, I made a study in which I measured how far into the future adolescents' thinking extended and what kinds of goals they had. The results were surprising (Nurmi, 1989). They showed that 11-year old adolescents' thinking extended 10 to 12 years into the future, whereas 18 -year olds' thinking extended 2 to 3 years. But the contents of 11-year old and 18-year old adolescent thoughts were very similar.

Second, I was reading at the same time two different literatures. The sociological work by Havighurst (1948) suggested that individuals face different developmental tasks in different age periods. For example, in adolescence young people are facing developmental tasks related to finding future education and occupation, forming identity, and acquiring social skills for intimate relationships. In turn, in early adulthood, individuals were facing developmental tasks concerning entering into working life, developing intimate relationships, and founding family and taking care of children. Although Havighurst's notion looked very simple, it was in accordance with the empirical findings of my study. One explanation for why 11-year old adolescents' thinking extended further into the future than the thinking of 18-year olds was that the hopes of both age groups focused on same developmental tasks, that is, finishing education, starting a career, and founding a family. Since 11-year olds were further away from the actualization of these life events, their future thinking showed more 
extended time perspective than the thinking of 18-year olds (Massey, Gebhardt, and Garnefski, 2008; Nurmi 1991).

In turn, some work in the field of motivation suggested that motivation should be conceptualized, not as inner needs, but rather as a relation between individual inner motives and the objectives in reality to which they refer and by which they are satisfied (Nuttin 1984). This notion helped me to understand and further conceptualize adolescents' future hopes and goals. Namely, the contents of adolescents' hopes and goals concern the objectives in reality at which their motives refer to (e.g., future education and family). Many researchers also suggested that people construct different kinds of plans and strategies to attain their goals (Miller, Galanter, and Prigram 1958; Nuttin 1984). Consequently, young people need to explore future possibilities and related information, and, on the basis of this, create realistic plans and strategies to attain their future goals. Moreover, some scholars suggested that one important stage of behavioral regulation is the evaluation of to what extent individuals have attained their goals. Two kinds of psychological processes are important in this evaluation. The first stage of evaluating goal attainment is based on affects and affective responses (Weiner 1985). Namely, goal attainment leads immediately to positive affects, whereas goal non-attainment activates negative affects. In the second stage of evaluation, individuals begin to think what were the causes of goal attainment or non-attainment (Weiner 1985).

On the basis of these theoretical notions and some empirical findings I created a theory of adolescents' future-orientation (Figure 2; Nurmi 1991). The theory included two key ideas. First, adolescents' future orientation includes a three stage process (Miller et al. 1958; Nuttin 1984; Weiner 1985): adolescents construct concrete hopes and goals on the basis of their individual motivation; to attain their goals they need to formulate various plans and strategies; and, during their efforts to attain their goals, they evaluate their progress in terms of affects and causal attributions. Second, on the basis of life-course sociology (Havighurst 1948), I described future orientation as an interactive process between individual future orientation and the age-related sociocultural environment. In order to construct realistic goals, young people need to compare their goals to agerelated developmental tasks and normative life events. Similarly, to create realistic means to attain their goals, adolescents have to compare their plans and strategies to the action opportunities in their living environments. Also, to evaluate their progress in goal attainment, individuals need to compare the outcomes of their previous efforts to various cultural standards and deadlines for dealing key developmental tasks.

The theory summarized in Figure 2 is a typical theory, because it operates on a relatively abstract and general level, it is built on the basis of 


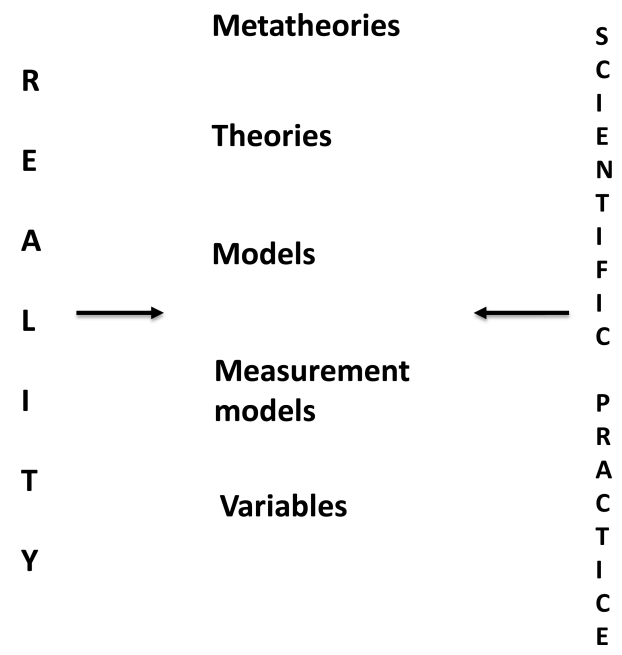

Figure 2. Modeling as impacted by reality and scientific practice

other theories and cumulative evidence, it provides a heuristic tool for formulating models that can be tested empirically, and no single study or experiment can falsify it.

Example 2: Personal Goals and Role Transitions During University Studies

As an example of creating a model and testing it by investigating interindividual variation across several longitudinal measurements I describe a study that I conducted together with Salmela-Aro and Aunola (SalmelaAro, Aunola and Nurmi 2007). This example describes the level of modeling, as described in Figure 1, by focusing on inter-individual variation.

According to the life-span model of motivation (Nurmi 2004; SalmelaAro et al. 2007), individuals' motivation and personal goals are embedded into their life-span development in at least three ways. First, the agegraded environments people face during a particular stage of their lives, i.e., developmental tasks, normative demands, and role transitions, play an important role in channeling the kinds of motives and personal goals people construct at a certain stage of their lives (Nurmi 1992; Nurmi 2004). Second, because the developmental tasks, challenges, and opportunities people experience change due to their earlier decisions, commitments, and related role transitions, people also need to adjust their personal goals to deal with changing life situations. A few previous studies have shown that people continuously adjust their personal goals to cope 
with changing environments. For example, Salmela-Aro and Nurmi (1997) found that the life situation of young adults, such as being married and having children, predicted their subsequent family-related goals. The third mechanism which relates motivation to life-span development is that individuals do not only adjust to the changes in their developmental environments but they also direct their development and select a variety of environments (Lerner 1982). An individual's motivation and personal goals play an important role in this selection process (Nurmi 2004). For example, young adults' family-related goals predict subsequent moves towards marriage or cohabitation (Salmela-Aro and Nurmi, 1997).

To test our model, we set several hypotheses: (1) Young people's personal goals change during the third decade of their lives while they progress through their university studies ([channeling] Nurmi 2004; SalmelaAro et al. 2007). (2) Biological age explains changes in personal goals, as women approach age of limited opportunity for getting pregnant. (3) Life transitions and related commitments, such as forming a family and having children, graduation, and entrance into employment predict the changes in personal goals ([adjustment] Nurmi 2004; Salmela-Aro et al. 2007). (4) Young people's personal goals predict their subsequent life events, transitions and commitments (selection).

To test these hypotheses, 297 university students completed the revised Personal Project Analysis, a life-event questionnaire, and Beck's depression inventory five times over a ten-year period. The results were analyzed by using growth curve modeling.

The results of the study showed first (hypothesis 1) that during the first three years of university studies the participants increasingly engage in personal goals related to education, after which there was a disengagement from such goals. Moreover, the number of personal goals related to friends and traveling decreased during university studies. In contrast, young adults showed an increasing engagement in work-related personal goals as their time at the university passed. Similarly, the amount of personal goals focusing on future issues of family, children and health increased particularly in the later years of the follow up.

As was expected (hypothesis 2), the results showed further that the older the participants were the more work- and family-related goals, and the less friend- and hobby-related goals they had. This result suggests that in addition to the stage of a particular institutional transition people were experiencing, their biological age contributed to their personal goals.

Next, we tested a hypothesis (3) concerning whether going through particular life transitions and forming related commitments would contribute to the changes in personal goals. The results provided support for hypothesis 3. Previous life-events in the interpersonal domain of life con- 
tributed to a high amount of personal goals in this particular life domain: the earlier the participants had married or had begun co-habiting, the more family-related goals they reported later on. Similarly, the earlier the young adults had graduated from the university, the more of a decrease they showed in education-related goals during their university years.

The final hypothesis (4) was that young people's personal goals would predict their subsequent life events, transitions and commitments (selection). The results provided evidence for the hypothesis: the more familyrelated goals young adults initially had, the earlier they had married or cohabited during the university years, and the earlier and more likely they were to have children later on.

This study is a typical example of how models are generated in psychology on the basis of broader theories, as well as how they are tested via modeling. After deriving hypotheses on the basis of the model, they are evaluated by investigating inter-individual differences in data.

\section{Example 3: Testing an Idiographic Statistical Model on Goal Progress and Work Exhaustion}

As another example of creating a model in psychology and testing it by using statistical modeling I describe a study that we carried out together with Salmela-Aro, Keskivaara and Näätänen (2008). This example describes the level of modeling, as described in Figure 1, by focusing on intra-individual variation. One of the key ideas of this kind of modeling of intra-individual variation is to understand better the mechanisms that underlie some associations between various phenomena (see Machamer, Derden, and Craver, 2000; Nurmi 2012)

The study was based on several assumptions. First, we expected that personal goals and related goal appraisals have an important role in people's ill-being, such as work-related exhaustion. The key reason for this assumption was that personal goals should play an important role in the ways in which individuals direct their behavior in different situations, such as at work, and particularly in their efforts to change the situation and their behavior in it (Austin and Vancouver 1996). Changing behavior might be assumed to provide a basis for an increase in well-being. There is also a substantial body of research showing that appraising one's goals as progressing well is associated with psychological well-being, life satisfaction, and low level of depression. An alternative possibility is, however, that high well-being and a low level of depression contribute to appraisals of goal progress, either because they are likely to increase people's effort to attain their goals or because they increase the optimism concerning goal progress. Although personal goals, and how people evaluate their progress in goal attainment, have been shown to direct people's lives over longer 
Socio-

cultural

context

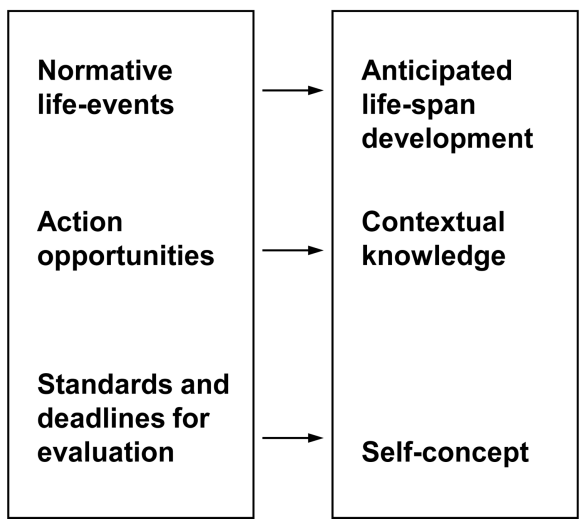

Future

orientation

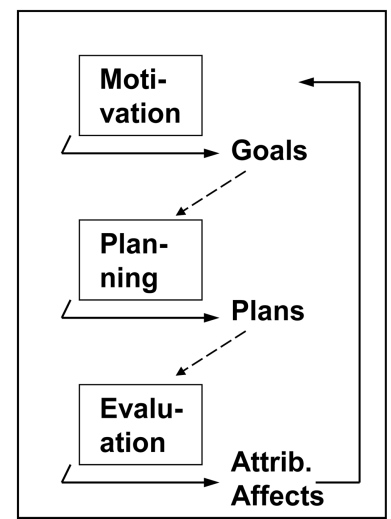

Figure 3. Future orientation in sociocultural context (from Nurmi, 1991)

time periods, such as years and even decades (Nurmi, Salmela-Aro, and Koivisto 2002; Salmela-Aro and Nurmi 1997), personal goals might also be assumed to have an impact on people's daily and weekly behavior.

Second, the recursive relationships between goal progress and workexhaustion were conceptualized as a dynamic system and analyzed in terms of intra-individual variation over time in time-series data. We had several reasons for using this approach. For example, no previous studies have examined how goal appraisals and well-being relate to each other within individuals over short time intervals. Moreover, although the idea of analysing individual change over time was introduced early on in psychology, this notion has attracted an increasing theoretical interest only during the past decade (Eye and Bergman 2003). Also, a new psychometric tradition has suggested that one needs to study an individual across time by focusing on intra-individual variation (Molenaar, Huizenga, and Nesselroade 2003). As was suggested by Browne and Nesselroade (2005), modeling of a dynamic, psychological process should include variables representing forces that cause change, variables on which the changes are manifested, and parameters that define a temporal flow in the relationships among and between the two kinds of variables.

In our study, weekly time-series data on participants' work-exhaustion and their appraisals of progress in their work-related goals were gathered over a one-year period during which they were participating in a groupbased psychotherapeutic intervention aimed at reducing their burnout 


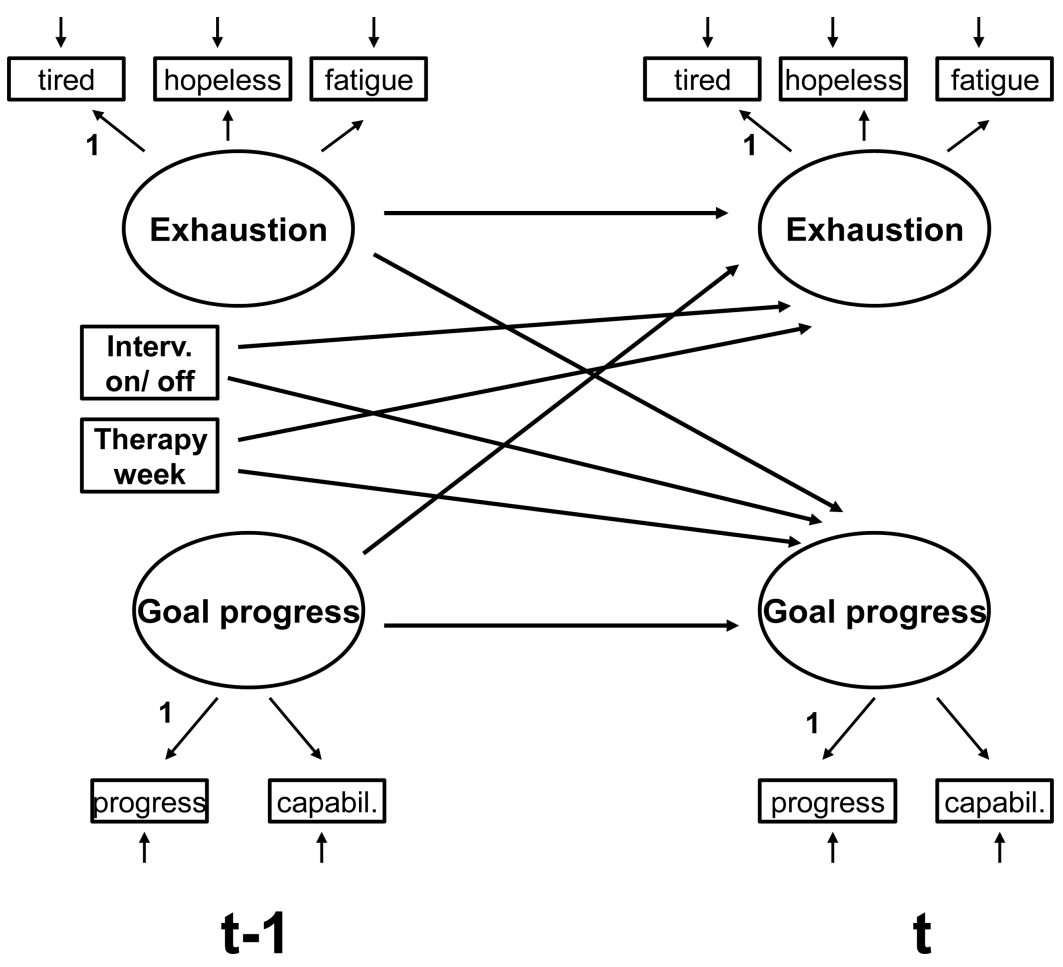

Figure 4. The tested time-series model concerning the stabilities and prospective associations between exhaustion and goal progress (from Nurmi \& al 2008)

(Salmela-Aro, Näätänen, and Nurmi 2004). The stabilities and lagged relationships between work-exhaustion and progress in work-related goals were examined by means of dynamic factor analysis (DFA), carried out separately for each individual. The DFA is regarded as a powerful tool in investigating intra-individual patterns of change, because it generates information on the processes of change in intra-individual variability and to patterning of relationships among factors over time (Molenaar and al. 2003).

Our study had the following goals (Figure 4): (1) Does progress in work-related goals predict work-related exhaustion a week later? (2) Does work-exhaustion predict progress in work-related goals a week later? (3) To what extent do the stabilities of, and the lagged relationships between work-exhaustion and progress in work-related goals vary across individuals? (4) Do individual dynamics between work-exhaustion and progress in work-related goals predict the outcomes of therapy in terms of 
changes in burnout, work-related stress, depression and self-esteem during the intervention?

The results of our study showed, first, that the lagged paths between progress in goals and work-exhaustion varied greatly across the participants. For a few participants, a high level of goal progress during a given week predicted a low level of work-exhaustion the next week, whereas for a few others a high level of goal progress predicted a high level of exhaustion a week later. Second, for a few participants a high level of workexhaustion predicted a low level of goal progress a week later, whereas for a few it predicted a high level at progress in work-related goals. The majority of the participants, in both cases, were somewhere in between.

Third, the results of our study showed that the lagged relationships between the weekly measurement of work-related goal appraisals and workexhaustion showed some interesting internal dynamics. The more stable the participants' weekly appraisals of goal progress were, the more likely their progress in work-related goals was to decrease work-exhaustion a week later. Similarly, the more stable their weekly work-exhaustion was, the more it decreased participants' appraisals that their goals had progressed well one week later.

Fourth, our results showed that the individual parameters of the dynamic system predicted the outcomes of group psychotherapy. For example, the more the participants' goal progress appraisals fluctuated weekly, the more their depressive symptoms decreased and the more their wellbeing increased during the therapeutic intervention. These results suggest that the more an intervention causes weekly fluctuation in appraisals of goal progress, the more benefits the intervention is likely to bring. The results showed further that the more the participants' exhaustion fluctuated weekly, the more their work-related stress decreased during the intervention.

This study used modeling to test the extent to which goal progress and work-exhaustion showed cross-lagged associations over time at the level of individual participants. The CFA models tested in the study are untypical in psychology as the focus was on intraindividual rather than interindividual variation. In other words, we did not test whether the model applies to the sample of participants as a group but rather to what extent the model is in accordance with the developmental pattern that individual participants show over time.

\section{Critical Issues of Modeling as a Mean to Understand Reality}

In their efforts to understand some phenomena, scientists observe reality and construct theories and models to explain their observations, and, thereby, create deeper understanding of some part of reality. The process is 
interactive: while observations lead to building certain models and theories, models and theories also direct the ways in which scholars conduct their observations. This interactive process does not only include straightforward analytical thinking and logic, or statistical testing but it has also has some caveats that deserve further discussion.

First, when conducting research scientists do not start from scratch: they have been educated to use certain scientific principles, to plan their research on the basis of some meta-theories, and to follow some scientific traditions and guidelines. Even though scientific education is crucial for understanding how to do science, it also leads to some problems. For example, previous traditions, meta-theories and theories are likely to influence the ways in which the scholars conduct observations of a particular phenomenon. In this way, science is a constructive activity which is led by scientists' models and theories that do not only direct their observations but also sometimes distort them. As another side of the coin, the lack of theoretical understanding of a certain research field may also lead to problems in research. If a scientist does not know a certain research field and relevant theories, they may set research questions that lead them to investigate phenomena in inappropriate ways or focus on research topics that do not add to understanding of a particular research field.

Second, differences in traditions, theories and conceptualizations in some research field may inhibit discussion between scientists, even if they are interested in the same phenomenon. In this sense scientists form "language communities" within certain paradigms and theories, and belonging to a certain community may hinder interactions with scientists from another community. As science is collective activity in which only cumulative evidence provides a reliable way to test theories, such lack of discussion may be detrimental for a particular research field.

A related issue is the extent to which scientists should rely on metatheories, theories, and constructs that are used and widely agreed to by the majority of the researchers in a certain field. In science shared conceptualizations and theories are common. In turn, in many social sciences there are many alternative theories that employ different constructs to conceptualize the same phenomenon. Widely agreed theories and conceptualizations provide a basis for cumulative evidence but may also lead to conservative scientific practice; several alternative theories, in turn, inhibit the cumulative evidence concerning certain phenomenon.

The fifth important issue in modeling and conducting research is how much a particular model should be able of explain of the variation of the variables that are used to test the particular model. In psychology, some people are happy to explain $10 \%$ of the variation of their observations, 
whereas some others aim to explain $20 \%, 30 \%$ or $50 \%$ of the variation. In some of the natural sciences the requirement is typically much tighter. This topic becomes even more important in applied research. For example, if we plan an intervention or prevention of some problems people face in their lives (e.g. reading difficulties, depression, marital problems) on a basis of a certain model, what is the satisfactory amount of variation that the model need to explain of the particular behavior, that the intervention is targeted to, before we can start to build up an intervention?

\section{Conclusions}

In this article I discussed modeling in one particular science, that is, psychology. Modeling was described as an interactive process between a phenomenon under study and different levels of theoretical conceptualizations that vary in respect to how directly they can be related to empirical observations and at what level of generalization they operate.

The discussion of modeling also has consequences for philosophy of science and empirical research. First, there is a need for a broader discussion between different disciplines concerning the interactive process between theories, models and observations. This does not mean that modeling should be understood in an identical way in all disciples. However, such discussion between disciplines can be expected to increase our understanding of key issues of modeling within a particular science. Second, we also need discussion between the scholars who are interested in philosophy of science, those who actually conduct empirical research, and those who are specialized in statistical and mathematical modeling of various phenomena. This kind of discussion can help us as scientists to better understand the implicit assumptions that we deploy in our scientific practice. Third, scientists in different disciplines should be as specific as possible, and also as open as possible concerning the meta-theories, theories and paradigms that they have applied in their research. These should also be discussed in the contexts of their findings, particularly in respect to how theoretical implications might have influenced the results. Fourth, scientists should also evaluate the extent to which their observations provide support for a particular theory, and if support is not found, suggest alternative theories to be tested in future research. Finally, scientists should pay more attention to the explanatory power of their models in explaining the variation in their data. They should specify how much we need to explain the variation in order to claim that our model satisfactory describes a particular phenomenon or that our model provides an appropriate basis for any efforts to change reality by means of intervention and prevention efforts. 


\section{References}

Austin, James T, and Vancouver, Jeffrey B. 1996. "Goal Constructs in Psychology: Structure, Process, and Content." Psychological Bulletin 120:338-75.

Browne, Michael W., and Nesselroade, John R. 2005. "Representing Psychological Processes with Dynamic Factor Models: Some Promising Uses and Extensions of ARMA Time Series Models." Pp. 415-52 in Advances in Psychometrics: A Festschrift for Roderick P. McDonald. Edited by Albert Maydeu-Olivares and John J. McArdle. Mahwah, NJ: Erlbaum.

Eye, von, Alexander and Bergman, Lars R. 2003. "Research Strategies in Developmental Psychopathology: Dimensional Identity and the Person-Oriented Approach." Development and Psychopathology 15:553-80.

Havighurst, Robert. 1948. Developmental Tasks and Education. New York: McKay.

Massey, Emma K., Gebhardt, Winifred A. and Garnefski, Nadia. 2008. "Adolescent Goal Content and Pursuit: A review of the Literature from the Past 16 Years." Developmental Review 28: 421-60.

Lerner, Richard. 1982. "Children and Adolescents are Producers of Their Development." Developmental Review 2:242-309.

Mischel, Walter, and Grusec, Joan. 1967. "Waiting for Rewards and Punishments: Effects of Time and Probability of Choice." Journal of Personality and Social Psychology 5:24-31.

Miller, George, Galanter, Eugene and Pribram, Karl. 1960. Plans and the Structure of Bebavior. New York: Holt, Rinehart and Winston.

Molenaar, Peter C. M., Huizenga, Hilde M. and Nesselroade, John R. 2003. "The Relationship Between the Structure of Interindividual and Intraindividual Variability: A Theoretical and Empirical Vindication of Developmental Systems Theory." Pp. 339-60 in Understanding Human Development: Dialogues with Lifespan Psychology. Edited by Ursula M. Staudinger and Ulmann Lindenberger. Dordrecht, Netherlands: Kluwer Academic Publishers.

Neisser, Ulric. 1976. Cognition and Reality: Principles and Implications of Cognitive Psychology. San Francisco: Freeman.

Nurmi, Jari-Erik. 1989. "Development of Orientation to the Future During Early Adolescence: A Four-Year Longitudinal Study and Two CrossSectional Comparisons." International Journal of Psychology 24:195-214.

Nurmi, Jari-Erik. 1992. "Age Differences in Adult Life Goals, Concerns, and Their Temporal Extension: A Life Course Approach to FutureOriented Motivation." International Journal of Behavioral Development 15:487-508 
Nurmi, Jari-Erik. (2004). "Socialization and Self-Development: Channeling, Selection, adjustment and Reflection." Pp. 85-124 in Handbook of Adolescent Psychology. Edited Richard Lerner \& Lawrence Steinberg. New York: Wiley.

Nurmi, Jari-Erik. 2012. "Foundational Issues in Investigating Development as Interindividual Variation.” Pp. 231-246 in Handbook of Developmental Research Methods. Edited by Brett Laursen, Todd Little, and Noel Card. New York: Guilford.

Nurmi, Jari-Erik, Salmela-Aro, Katariina and Koivisto, Petri. 2002. "Goal Importance and Related Achievement-Beliefs and Emotions during the Transition from Vocational School to Work: Antecedents and Consequences." Journal of Vocational Behavior 60:241-61.

Nurmi, Jari-Erik, Salmela-Aro, Katariina, Keskivaara, Pertti and Näätänen, Petri. 2008. "Confidence in Work-Related Goals and Feelings of Exhaustion during a Therapeutic Intervention for Burnout: A Time Series Approach." Journal of Occupational and Organizational Psychology 81:277-97.

Nuttin, Joseph R. 1984. Motivation, Planning and Action. A Motivational Theory of Behavioral Dynamics. Developmental Review. Hillsdale, N.J.: Lawrence Erlbaum.

Salmela-Aro, Katariina, Aunola, Kaisa and Nurmi, Jari-Erik. 2007. "Personal Goals During Emerging Adulthood: A 10-Year Follow-Up." Journal of Adolescent Research 22:690-715.

Salmela-Aro, Katariina and Nurmi, Jari-Erik. 1997. "Goal Contents, WellBeing and Life Context During Transition to University: A Longitudinal Study." International Journal of Behavioral Development 20:471-91.

Salmela-Aro, Katariina, Näätänen, Petri, and Nurmi, Jari-Erik. 2004. "The Role of Work-Related Personal Projects During Two Burnout Interventions: A Longitudinal Study.” Work E Stress 18:208-30.

Salmela-Aro, Katariina, Nurmi, Jari-Erik, Saisto, Terhi and Halmesmaki, Erja. 2000. "Women's and Men's Personal Goals During the Transition to Parenthood.” Journal of Family Psychology 14:171-86.

Suppes, Patrick. 1962. "Models of Data." Pp. 252-261 in Logic, Methodology, and Philosophy of Science. Edited by E. Nagel, P. Suppes, and A. Tarski. Stanford: Stanford University Press.

Trommsdorff, Gisela, Lamm, Helmut and Schmidt, Rolf W. 1979. "A Longitudinal Study of Adolescents' Future Orientation (Time Perspective)." Journal of Youth and Adolescence 8:131-47.

Weiner, Bernard 1985. "An Attributional Theory of Achievement Motivation Review and Emotion.” Psychological Review 92:548-73. 